\title{
Erratum to: TelEMA: a low-cost and user-friendly telephone assessment platform
}

\author{
Katya C. Fernandez • Matthew R. Johnson • \\ Thomas L. Rodebaugh
}

Published online: 20 September 2013

(C) Psychonomic Society, Inc. 2013

\section{Erratum to: Behav Res}

DOI: 10.3758/s13428-012-0287-9

In Table 2, the Beta estimate for Trait social anxiety predicting Negative affect should be changed from 5.881 to 0.023 , and it's now nonsignificant (i.e., no double asterisks). Though a more minor correction, the Beta estimate for State social anxiety predicting Depression should be changed from .200 to .198 .

On the tenth page of the article, under Results, the second sentence should also be changed to: "Trait social anxiety did not significantly predict negative affect $(p=.594)$, positive affect $(p=.622)$, or depression ( $p=.167)$ over time."

The online version of the original article can be found at http://dx.doi.org/ 10.3758/s13428-012-0287-9.

K. C. Fernandez $(\bowtie) \cdot$ T. L. Rodebaugh

Department of Psychology, Washington University in St. Louis,

1 Brookings Drive, Campus Box 1125,

St. Louis, MO 63130, USA

e-mail: fernandez@wustl.edu

M. R. Johnson

Coordinated Science Laboratory, University of Illinois at

Urbana-Champaign, 1308 W. Main St.,

Urbana, IL 61801, USA 